\title{
Nonstationarity of low flows and their timing in the eastern United States
}

\author{
S. Sadri ${ }^{1}$, J. Kam ${ }^{1,2}$, and J. Sheffield ${ }^{1,3}$ \\ ${ }^{1}$ Princeton University, Princeton, NJ, USA \\ ${ }^{2}$ Cooperative Institute for Climate Science, Princeton, NJ, USA \\ ${ }^{3}$ University of Southampton, Southampton, UK
}

Correspondence to: J. Sheffield (justin@ princeton.edu)

Received: 26 January 2015 - Published in Hydrol. Earth Syst. Sci. Discuss.: 5 March 2015

Revised: 26 November 2015 - Accepted: 16 January 2016 - Published: 8 February 2016

\begin{abstract}
The analysis of the spatial and temporal patterns of low flows as well as their generation mechanisms over large geographic regions can provide valuable insights and understanding for climate change impacts, regional frequency analysis, risk assessment of extreme events, and decisionmaking regarding allowable withdrawals. The goal of this paper is to examine nonstationarity in low flow generation across the eastern US and explore the potential anthropogenic influences or climate drivers. We use nonparametric tests to identify abrupt and gradual changes in time series of low flows and their timing for 508 USGS streamflow gauging sites in the eastern US with more than 50 years of daily data, to systematically distinguish the effects of human intervention from those of climate variability. A time series decomposition algorithm was applied to 1-day, 7-day, 30-day, and 90-day annual low flow time series that combines the Box-Ljung test for detection of autocorrelation, the Pettitt test for abrupt step changes and the Mann-Kendall test for monotonic trends. Examination of the USGS notes for each site showed that many of the sites with step changes and around half of the sites with an increasing trend have been documented as having some kind of regulation. Sites with decreasing or no trend are less likely to have documented influences on flows. Overall, a general pattern of increasing low flows in the northeast and decreasing low flows in the southeast is evident over a common time period (19512005), even when discarding sites with significant autocorrelation, documented regulation or other human impacts. The north-south pattern of trends is consistent with changes in antecedent precipitation. The main exception is along the mid-Atlantic coastal aquifer system from eastern Virginia
\end{abstract}

northwards, where low flows have decreased despite increasing precipitation, and suggests that declining groundwater levels due to pumping may have contributed to decreased low flows. For most sites, the majority of low flows occur in one season in the late summer to fall, as driven by the lower precipitation and higher evaporative demand in this season, but this is complicated in many regions because of the presence of a secondary low flow season in the winter for sites in the extreme northeast and in the spring for sites in Florida. Trends in low flow timing are generally undetectable, although abrupt step changes appear to be associated with regulation.

\section{Introduction}

Low flows - the minimum flow in a river during the dry periods of the year - are an important part of the streamflow regime that has direct impacts on water supply, water quality, and ecosystem health (Bradford and Heinonen, 2008). Knowledge of low flow characteristics and generation mechanisms over large geographic regions is important for regional frequency analysis, risk assessment of extreme events, decision-making regarding allowable basin withdrawals and water quality, and understanding climate change impacts (Tallaksen and van Lanen, 2004). For example, in every state of the US, estimates of low flow statistics are needed for issuing and/or renewing of National Pollution Discharge Elimination System permits, as required by provisions in the Clean Water Act of 1977 (US Senate, 2002). Furthermore, low flow periods are critical to aquatic habitats due to potentially low 
dissolved oxygen concentrations and/or high pollutant concentration (US Senate, 2002). However, the study of low flow statistics and patterns have received little attention in comparison to droughts and floods (Kroll et al., 2004). Poff et al. (1997) emphasize the need of paying particular attention to low flows because they present critical stresses and opportunities for a wide array of riverine projects.

Low flows are generally controlled by subsurface flows sourced from groundwater that maintain flows during the dry periods of the year, such that low flow volumes are related to the physiological and geological make up of the area. In some regions, where precipitation is significant in the warm season, surface flows also play a role in maintaining low flows. However, our understanding of these low flow generating mechanisms is limited (Smakhtin, 2001), and is further compounded by the sensitivity of low flows to changes in climate, land use and human impacts on stream flow (Rolls et al., 2012). For example, large-scale teleconnections may play an important role in driving inter-annual to multi-decadal changes in streamflow (e.g., Mauget, 2003) and low flows (e.g., Giuntoli et al., 2013). Regulation generally introduces nonstationarity into low flow time series that impedes the development of regional or at-site frequency analysis models. In most instances, such models show a high standard error between modeled and observed quantiles (Kroll et al., 2004).

In the eastern United States (defined as the area covering the 20 ecoregions of the eastern US; USGS, 2012), both direct anthropogenic and climate influences may have impacted low flows, including land use change impacts via changes in sub-surface flow and groundwater recharge, direct impacts on flows via reservoirs and other streamflow management, and changes in precipitation and evaporation that have altered recharge. In particular:

1. In the US, more than $85 \%$ of the surface runoff is artificially controlled and nearly 1 million km of rivers are affected by dams (Poff et al., 1997). Surface water covers $4.5 \%$ of the eastern US, and the majority of streams have been flagged by the US Geological Survey (USGS) as regulated. The USGS estimates that the spatial extent of surface water increased by $1.3 \%$ during 19732000, with most of this increase in the southern Coastal Plain and southern Florida Coastal Plain (USGS, 2012) and associated with reservoir developments required to meet the needs of the expanding population. Figure 1a shows the location of major dams in the eastern US (defined as those 50 feet or more in height, or with a normal storage capacity of 5000 acre feet $\left(\sim 6200000 \mathrm{~m}^{3}\right)$ or more, or with a maximum storage capacity of 25000 acre feet $\left(\sim 30800000 \mathrm{~m}^{3}\right)$ or more; USACE, 2012). Generally dams and reservoirs are considered the largest man-made regulations on streamflow, but other sources include farm ponds, surface water extraction, inter-basin transfers, and wastewater treatment plant discharge (e.g., Walker and Thoms, 1993; Acre- man et al., 2000; Brandes et al., 2005; Thomas, 2006; Deitch et al., 2009; Kustu et al., 2010).

2. The eastern US has gone through significant land use change over the past several decades. For example, between 1973 and 2000, $8.2 \%$ of the $23620000 \mathrm{~km}^{2}$ of the northeastern ecoregion and $8.9 \%$ of the $30000000 \mathrm{~km}^{2}$ of the southeastern ecoregion experienced changes associated with active timber harvesting and replanting, which may have impacted low flows and related environmental and ecosystem well-being (USGS, 2012). Furthermore, in the expanding urbanized areas of the region with high levels of impervious ground, infiltration has decreased, which may have led to a decrease in groundwater recharge and low flow volumes (USGS, 2013). On the other hand, urbanization can lead to increases in low flows because of leakages from water supply and wasterwater pipes, direct wastewater discharge, reduced evapotranspiration, and water imports that can offset groundwater pumping (e.g., Brandes et al., 2005).

3. The region is one of the wettest parts of the US, receiving $700-1600 \mathrm{~mm}$ of precipitation per year. However, due to population growth and associated increased use of surface and groundwater resources, the future is expected to bring water stress for this area (Averyt et al., 2013). Some of these changes are already being observed. For example, USGS (2013) reports on $3-10 \mathrm{~km}^{3}$ of depletion of unconsolidated and semi-consolidated sand and gravel aquifers of the eastern coast between 1900 and 2008. Overuse of surface water in turn does not allow recharge of groundwater, leading to groundwater depletion. In parts of the eastern US, groundwater resources have become limited and hence municipal and industrial water users are increasingly relying on surface waters (e.g., Daniel and Dahlen, 2002). Changes in both surface water and groundwater use have impacts on low flows.

4. Precipitation has likely changed over the past several decades (Karl and Knight, 1998; Small et al., 2006). Evaporation may have changed due to increasing atmospheric demand from higher temperatures (e.g., Walter et al., 2004), although direct measurements of evaporation are limited in spatial and temporal coverage. Each of these changes may impact on low flows and in some cases may combine to exacerbate or counteract changes in low flows. Warmer temperatures may have also impacted winter-time low flows, via changes in snow (Burakowski et al., 2008) and river ice (Hodgkins et al., 2005).

Past evaluations of changes in low flows over the eastern US have mainly been within studies on the entire US and often with respect to mean and high flows. Douglas et al. (2000) 
estimated trends in both flood and 7-day low flows for three major geographic regions in the US (eastern, Midwest, and western) over two time periods, 1959-1988 and 1939-1988, and found evidence of upward trends in low flows across the Midwest, but not in the eastern US. Other studies have attempted to explain the general patterns of low flow trends. For example, Small et al. (2006) analyzed trends in annual 7-day low flow, average, and high flows along with seasonal precipitation over individual basins in the US for 19481997. The number of sites shown to have statistically significant trends in low flows and fall precipitation in the eastern US was small and restricted to the south of Maine, western Pennsylvania, coastal areas of South Carolina, and western Florida. In the northeast and west of Pennsylvania, precipitation showed an increasing trend during the fall but not during the spring, and the increase in fall precipitation appeared to result in an increase in low flows in the northeastern areas. The only statistically significant decrease in the low flows was found in the southern Atlantic-Gulf region, west of Florida, consistent with the findings from Lins and Slack (1999). However, no specific reason for this decreasing trend was given. McCabe and Wolock (2002) examined historic changes in streamflow, using the annual minimum, median, and maximum daily streamflow at 400 sites across the US during 1941-1999. They found an increase in annual minimum and median daily streamflow around 1970 that primarily occurred in the eastern US as a step change, rather than a gradual trend. Andreadis et al. (2006) used model simulations to examine trends in soil moisture, runoff, and drought characteristics over the US for the period 19152003. They found increasing runoff over parts of the northeast, which was most evident during winter months, with decreases in hydrological and agricultural drought, and drying trends in the summer in the southeast, with increases in drought. These changes were attributed to changes in precipitation, and they speculated that increasing drought in the southeast was associated with higher atmospheric demand due to warming. Although these studies are generally consistent for the eastern US they tend to focus on the spatial pattern of trends in 7-day low flows only, and were limited to earlier periods available at the time of the study. Furthermore, these studies focused on sites that were deemed to have minimal anthropogenic influence, and so did not explore the role of anthropogenic influences, such as land cover change or water withdrawals (Brown et al., 2013).

The goal of this paper is to examine nonstationarity in low flow generation across the eastern US by attempting to identify time series that are potentially free of the effects of human intervention and examine these in terms of the impact of climate variability. A way to determine whether a river has been subject to anthropogenic influences, at least in terms of regulation, is to examine the site notes for the gauging station. However, site notes might not be available, complete, or accurate, and examining the notes for multiple sites can be unwieldy. Furthermore, whether a site is deter- mined to be regulated or not is often based on high flows and not on low flows. Here, we develop an approach that makes the simplification that the impact of human activities can be detected in the streamflow data in a systematic way. This is generally more efficient and can complement site notes or compensate for errors in them. Low flow time series (and flows in general) can show two general types of nonstationarity: gradually increasing or decreasing trends, and abrupt changes (Villarini et al., 2009) in the mean and/or variability. As McCabe and Wolock (2002) observe, the distinction between a gradual trend and a step change is important, particularly for climate-change impact studies, since climate change usually manifests as a trend and not a step change. We therefore make the simplification that step changes (abrupt and visually obvious) in the time series are indicative of an anthropogenic effect, and that gradual trends reflect a climate effect, which may be due to anthropogenic climate change or long-term persistence (Cohn and Lins, 2005). As it is possible that step changes may be driven by natural variability (e.g., McCabe and Wolock, 2008) this simplification is based on identifying abrupt and visually obvious step changes.

Our overall approach is to use nonparametric statistical tests to identify abrupt and gradual changes in the value and timing of n-day low flows, and identify stationary segments of the time series. Furthermore we analyze the covariability of low flows with antecedent precipitation to understand the influence of changes in precipitation and atmospheric demand (as quantified by potential evapotranspiration) on changes in low flows. The paper is organized as follows: Sect. 2 describes the streamflow data and the methodology, including the use of three straightforward and alreadyestablished statistical methods, for identifying nonstationarity in annual low flow time series. The results on the systematic identification and characterization of abrupt changes in low flow volumes and timing are presented in Sect. 3. The results on the variability and trends are given in Sect. 4. Finally, we discuss the results, the potential drivers of changes and their implications, and present conclusions in Sect. 5.

\section{Data and methods}

\subsection{Study area}

Our study area covers the eastern US from Maine in the northeast to Florida in the southeast and westwards to the Appalachian Mountains and the Mississippi River in the south, and is based on the 20 ecoregions of the eastern US (USGS, 2012). According to the USGS (2012), $52.4 \%$ of the eastern ecoregion in 2000 was forest. However, both forests and agriculture have been in decline since 1973 and instead, urbanization has increased and continues to increase. Most land cover change has occurred in the southeast and is associated with forest harvesting, agricultural abandonment, and development (USGS, 2012). Changes in the northeast have 


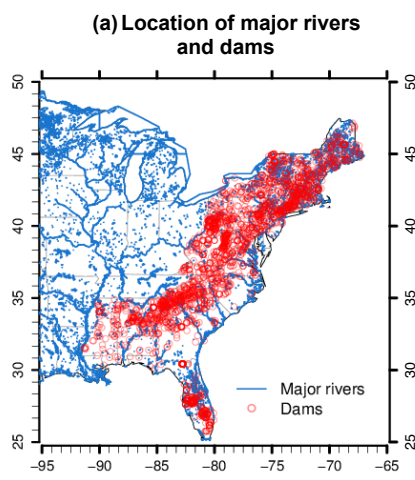

(b) USGS sites with $>50$ years of complete data

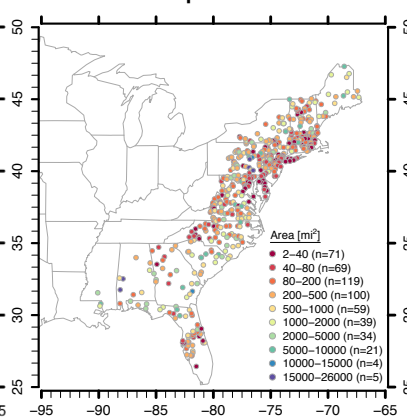

(c) USGS flags of potential regulation/changes

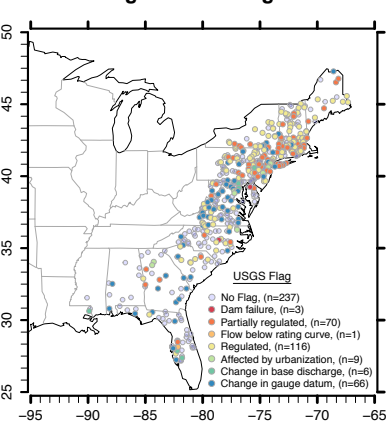

Figure 1. (a) Location of 2352 major dams in the eastern US. (b) Location of the 508 streamflow sites with 50 years or more of complete daily data. (c) Flagged sites according to the USGS.

(a) $Q_{7}$ low flow categories

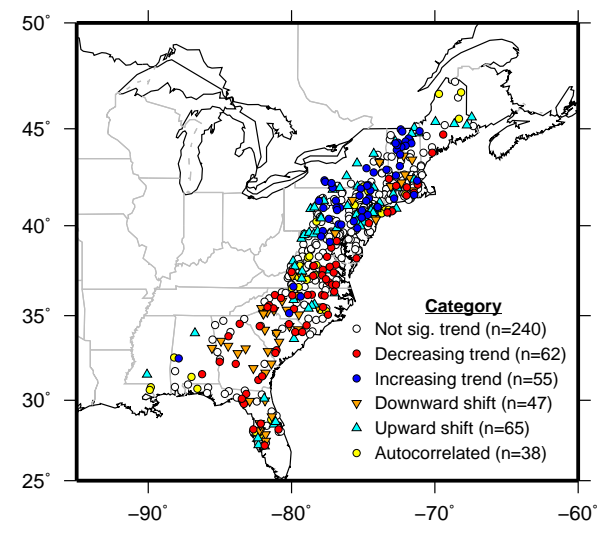

(b) $Q_{30}$ low flow categories

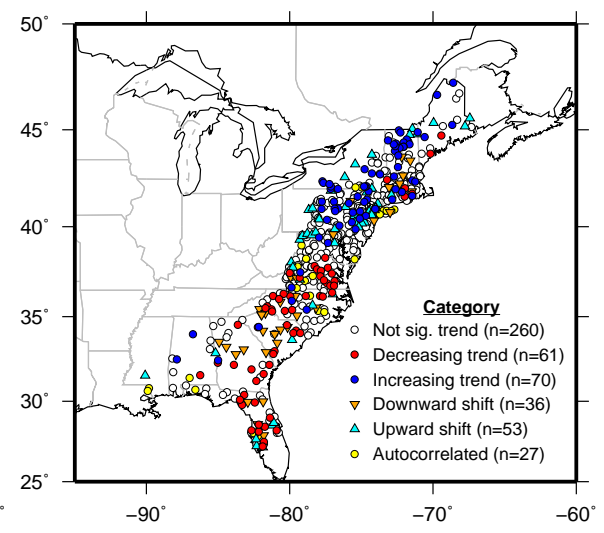

Figure 2. Categorization of nonstationarity of sites for Q7 and Q30.

been mostly associated with timber harvesting. Changes in the northern Central Appalachian region have been more heterogeneous and include examples of non-mechanical transitional change. Unlike the northeastern Coastal Plain, the southern Florida Coastal Plain has not experienced loss of agricultural land, but the largest decrease in surface water and significant loss of wetlands $(-2.4 \%)$. Changes in surface water in the southern Coastal Plain have primarily been due to urbanization (USGS, 2012).

The eastern US is one of the wettest parts of the country (Small et al., 2006), with average precipitation of about $1100 \mathrm{~mm} \mathrm{yr}^{-1}$, with maxima along the coastal plain and the mountains of the Appalachians. Part of the precipitation in the northeast falls as snow in the wintertime (Hayhoe et al., 2007). The eastern seaboard is susceptible to tropical storms and hurricanes during the Atlantic hurricane season, normally running from June to end of November, which enhance precipitation across southern and eastern parts, and play a role in alleviating drought (Kam et al., 2013). The El Niño-Southern Oscillation (ENSO) alters precipitation patterns across the southeast (Colby, 2008). Coastal extra- tropical cyclones bring the bulk of the wintertime precipitation to that region, forming along the natural temperature gradient of the Gulf stream before moving up the coastline (Gurka et al., 1995). Seasonally, there are slight changes in the precipitation distribution through the year. For example, Burlington, Vermont has a summer maximum and a winter minimum while Portland, Maine has a fall and winter maximum, with a summer minimum in precipitation. The water supply in the northeast is mainly derived from surface waters, which are heavily regulated to meet the water supply demand of urbanized areas such as New York City, although there has been an increase in groundwater sources in recent years. In contrast, the southeast, including Florida, lies on active aquifers (USGS, 2009). Projections of future climate indicate an increase in precipitation over the eastern US (Hayhoe et al., 2007; EPA, 2008) with consequences for changes in low flows across the region.

\subsection{Streamflow data}

Initially, 4878 sites with daily streamflow records were retrieved from the USGS National Water Information System 
(NWIS) (USGS, 2014) for the eastern US as defined by Hydrological Unit Codes (HUC) of 01, 02, or 03. Previous studies on low flows (e.g., Kroll and Vogel, 2002, Kroll set al., 2004; Douglas et al., 2000) have used the USGS HydroClimatic Data Network (HCDN; now updated to HCDN2009; Lins, 2012), in part because anthropogenic influences at these sites are deemed to be negligible, but as such, is limited to 204 sites across the domain. Of the original 4878 sites, 2811 were active in the 2000 s or later. Among these, 1092 sites had at least 30 years worth of daily data, 740 sites had 50 years or more, and 324 sites had 75 years or more. We used sites with at least 50 years of data as a balance between having enough of data at each site to identify long-term changes and the need to have many sites to characterize the spatial pattern of changes. We included only sites that did not have any missing years of daily data. This reduced the number of sites to 508 (Fig. 1b). Only 64 of these sites are in the HCDN-2009 database and have data for the common time period (1951-2005) that is used for analyzing trends across the domain (see Sect. 4). The drainage area of the candidate sites ranges from very small $\left(5-100 \mathrm{~km}^{2}\right)$ to large (38000-67000 $\mathrm{km}^{2}$ ), with the majority of areas between 200 and $500 \mathrm{~km}^{2}$, and these are spread fairly uniformly across the study area. The majority of the 508 sites are clustered on the eastern flank of the Appalachians and the northeast from eastern Virginia to New Hampshire. There is also a cluster of smaller catchments in central Florida. The mean, median, minimum and maximum record lengths are 74,72 , 50 , and 120 , respectively.

Based on the USGS site notes (available on the NWIS website), we identified sites that are flagged as: regulated, partially regulated, flow below the rating curve limit, dam failure, affected by urbanization, change of base discharge, and change of gauge datum. It should be noted that the USGS flags are developed for instantaneous peak flows and while it is uncertain whether these are directly applicable to low flows, it is likely that low flows are more sensitive to regulation. Some of the flags are unrelated to anthropogenic influences and are unlikely to have impacted the continuity of flow magnitudes, such as "change of base discharge", which is a level above which peak flows are recorded, or "change of gauge datum", which is the arbitrary zero gauge height for the rating curve. Figure 1c shows the location, flag type, and the number of the sites under each flag. Almost half of the sites have no flag and these are located throughout the domain. A few sites have more than one type of flag and we show the flag associated with a higher likelihood of the flows being affected (e.g., regulated). The majority of regulated or partially regulated sites are concentrated in the northeast, but this is also where the majority of all sites are located. The sites in the mid-Atlantic states are generally more affected by urbanization or have experienced a change of gauge datum. Overall, 198 sites out of 508 sites are flagged as affected in terms of anthropogenic influences. In the results section, we show how the results of our statistical methods compare with the USGS site flags that are related to regulation or some other human influence.

\subsection{Low flow indices}

We analyze four variants of low flows based on different timescales, to understand how nonstationarity is dependent on the timescale as the data become smoother, with implications for the detection of nonstationarity. The 1-day minimum low flow, Q1, is the annual minimum daily streamflow. The other three variants, Q7, Q30, Q90, are obtained by applying the same analysis to 7-day, 30-day, and 90-day moving average versions of the time series. Together, we refer to the four low flow variables as the n-day minimum flows. Q7 (dry weather flow) is the most widely used low flow statistic in the US (Kroll et al., 2004; Smakhtin, 2001), but the others are important for different applications, such as Q1 for ecological assessments and Q90 for reservoir operations. We also calculate the day of the year of low flows and use this to identify the primary (and in some regions the secondary) low flow season, as well as any long-term changes in timing. The primary season is defined as the 4-month period that contains the majority of the low flow occurrences, and the secondary season as the 4-month period that contains the majority of the remaining low flows. If the onset time of the low flow season for a site occurs 70 to $100 \%$ in a specific month, that site is assumed to have only one low flow season. The sites that have low flow events occurring $40-70 \%$ of the time in one month and $20-40 \%$ of the time in a different month are characterized as having two low flows seasons. We focus the presentation of the results on Q7 and Q30 flows.

\subsection{Identification of stationary time series}

A sequence of realizations of random variables, $Y$, is stationary if the distribution of the sequence is independent of the choice of starting point (Kendall et al., 1983; Ruppert, 2011). Determining stationarity of a time series is not straightforward (Lins and Cohen, 2011) and in practice, it is common to look at restricted measures of stationarity. A time series is defined as weakly stationary if it satisfies three criteria:

$$
\begin{aligned}
& E\left(Y_{i}\right)=\mu,(\forall i), \\
& \operatorname{Var}\left(Y_{i}\right)=\sigma^{2},(\forall i), \\
& \operatorname{Corr}\left(Y_{i}, Y_{j}\right)=\rho(|i-j|), \quad(\forall i, \forall j),
\end{aligned}
$$

where $\mu$ is the sample mean, $\sigma$ is the standard deviation and $\rho$ is the correlation, with $i$ representing one realization of a time series. This means that for a weakly stationary variable, the mean and variance do not change with time and the correlation between two values depends only on the lag (the time between values). Visual inspection of the time series and the changes therein can provide an indication in the attempt to assess stationarity, in that a change in the underlying process leads to changes in values that are obvious (Lins and Cohen, 2011; Koutsoyiannis, 2011; Serinaldi and Kilsby, 2015). 
We apply three tests to identify weak stationarity: (1) the Mann-Kendall test (Mann, 1945; Kendall, 1975), which tests for increasing or decreasing trends; (2) the Pettitt test (Pettitt, 1979), which tests for abrupt changes or change points; and (3) the Ljung-Box test (Ljung and Box, 1978), which tests for autocorrelation. An identified change in the mean by either of the first two tests would rule out stationarity, except in the case of autocorrelated data, for which the Pettitt and Mann-Kendall tests will characterize too many sequences of the time series as having a step or trend and therefore increase the rejection rate of the null hypothesis of no change (Douglas et al., 2000; Serinaldi and Kilsby, 2015). Therefore, analysis of autocorrelation is carried out before conducting the Mann-Kendall and Pettitt tests. Even when a site is identified as nonstationary, further analysis is required to understand the overall regime of the data at such a site. For example, the time series may have two separate stationary regimes with one change point in between or an overall trend. We then assume that the change year corresponds to human intervention, which is generally borne out by investigating the site notes.

\subsection{Decomposition algorithm}

The three statistical tests (Ljung-Box, Pettitt and MannKendall) were combined into a recursive algorithm to identify nonstationarity in the low flow time series and decompose the series into potentially stationary sub-series. In the first step of the algorithm, a Ljung-Box test with 20 lags was applied to the entire time series of each site, and sites with significant overall autocorrelation (5\% significance level) were identified. The Ljung-Box test identifies sites that are nonstationary and is able to identify sites with abrupt changes because the series of values before the change appear to be autocorrelated relative to the values after the change, and vice versa. This was confirmed by visual inspection of the time series. For the sites with significant overall autocorrelation, we then applied the Pettitt test (5\% significance level) to confirm the existence of any step change and identify its timing. The series were pre-whitened to remove lag-1 autocorrelation using the trend-free pre-whitening method of Yue and Wang (2002) and implemented by Kumar et al. (2009). It is necessary to identify sites with potential step changes using the Ljung-Box test first because the Pettitt test will identify step changes in time series with gradual trends. Similarly the MK test will identify gradual trends in series with step changes. If a significant change is found by the Pettitt test, the series is split into two parts either side of the step change. Each part is assumed to be a new series at the same location, and if it has a record length of 30 years or more, the decomposition algorithm is applied again. If the length is less than 30 years, the site is removed from further consideration. If a statistically significant step change is not identified, we note that the series is autocorrelated overall. We then applied the Mann-Kendall (MK) test (5\% significance level) on the re- maining sites to identify statistically significant trends in the data. Again, the series were pre-whitened to remove lag-1 autocorrelation. The series and sub-series are assigned categories as follows:

- Category 1: Non-autocorrelated site with no trend $(\mathrm{MK}=0)$;

- Category 2: Non-autocorrelated site with a statistically significant decreasing trend $(\mathrm{MK}=-1)$;

- Category 3: Non-autocorrelated site with a statistically significant increasing trend $(\mathrm{MK}=1)$;

- Category 4: Autocorrelated site with statistically significant step change, time series split and the sub-series re-categorized recursively;

- Category 5: Autocorrelated site with no step change.

\section{Stationarity results}

\subsection{Categorization of sites}

Figure 2 shows the spatial distribution and the number of sites in each category after the first recursive level of the decomposition algorithm. The results for Q7 and Q30 low flow metrics are presented for the available length of record at each site, which ranges between 1891 and 2011. No site has a record length less than 50 years and no site has any gap in the n-day low flow series. As we move from Q7 to Q30, a larger number of sites appear stationary (category 1) and the number of sites identified using the Pettitt test as having an abrupt shift in the time series (category 4) decreases. The algorithm re-applies the Pettitt test to category 4 sites to identify useable sub-series. For example, the Q7 time series of 112 sites are split into two parts, which are subjected to further categorization.

Figure 3 summarizes the time periods that were identified as useable at each step of the recursive algorithm for all sites for Q7. The vertical axis shows the site number from 1 to 508 ordered from the lowest to highest latitude. Therefore, site 1 is the most southerly and site 508 is the most northerly. The left panel of Fig. 3 shows the record length of sites, which, in the first step of categorization, had no significant autocorrelation. These sites are colored according to whether they contain a step change, have a significant trend or have no trend. The middle panel shows the sites identified in step 1 with a step change, with each series split into two parts. The two parts of the series are again colored according to whether they contain a step change or have a trend. The right panel shows the parts of the time series that were recovered in the third step of the decomposition algorithm. As long as the record length is greater than or equal to 30 years the algorithm is applied recursively on the remaining parts of the time series. The number of sites shown in the right panel is small but their data are still useful for subsequent analysis. 
Table 1. Comparison of the number of streamflow gauging sites in each category of the decomposition algorithm and their USGS flags for Q7. DamFail: dam failure; RegPar: partially regulated; Reg: regulated; Urban: affected by urbanization.

\begin{tabular}{|c|c|c|c|c|c|c|c|c|}
\hline Category & $Q_{7}$ & $Q_{30}$ & Flag & $Q_{7}$ & $Q_{30}$ & Flag type & $Q_{7}$ & $Q_{30}$ \\
\hline \multirow[t]{5}{*}{ No trend } & 240 & 260 & Flagged & 87 & 91 & DamFail & 1 & 2 \\
\hline & & & & & & RegPar & 33 & 37 \\
\hline & & & & & & Reg & 51 & 48 \\
\hline & & & & & & Urban & 2 & 4 \\
\hline & & & Not flagged & 153 & 169 & & & \\
\hline \multirow[t]{5}{*}{ Decreasing trend } & 62 & 61 & Flagged & 10 & 6 & DamFail & 0 & 0 \\
\hline & & & & & & RegPar & 3 & 1 \\
\hline & & & & & & Reg & 5 & 5 \\
\hline & & & & & & Urban & 2 & 0 \\
\hline & & & Not flagged & 52 & 55 & & & \\
\hline \multirow[t]{5}{*}{ Increasing trend } & 55 & 70 & Flagged & 23 & 37 & DamFail & 0 & 0 \\
\hline & & & & & & RegPar & 8 & 13 \\
\hline & & & & & & Reg & 15 & 24 \\
\hline & & & & & & Urban & 0 & 0 \\
\hline & & & Not flagged & 32 & 33 & & & \\
\hline \multirow[t]{5}{*}{ Step change } & 111 & 89 & Flagged & 64 & 53 & DamFail & 1 & 0 \\
\hline & & & & & & RegPar & 21 & 16 \\
\hline & & & & & & Reg & 38 & 32 \\
\hline & & & & & & Urban & 4 & 5 \\
\hline & & & Not flagged & 48 & 36 & & & \\
\hline \multirow[t]{5}{*}{ Autocorrelated } & 38 & 27 & Flagged & 13 & 10 & DamFail & 1 & 1 \\
\hline & & & & & & RegPar & 4 & 2 \\
\hline & & & & & & Reg & 7 & 7 \\
\hline & & & & & & Urban & 1 & 0 \\
\hline & & & Not flagged & 25 & 17 & & & \\
\hline
\end{tabular}

\subsection{Comparison with USGS flags}

Table 1 shows the breakdown of the number of sites in each category and the relation to USGS flags for Q7 and Q30, and indicates that in every category, anthropogenic influences are documented by the USGS. For Q7, the majority of sites in category 4 (57\%; step change) are flagged by the USGS as somehow affected. This suggests that the algorithm has some skill in identifying managed or altered flow series. However, there are also many sites in category 1 (36\%; no trend), 2 (16\%; decreasing trend) and 3 (42\%; increasing trend) that are also flagged (see Fig. 4) suggesting that anthropogenic impacts for these sites are minimal and/or are overwhelmed by any climate or land use induced changes. The fact that the majority of stationary sites (category 1 ) are not flagged is encouraging. Figure 4 shows all the sites from each of the five categories that have no anthropogenic flag for Q7: 310 out of 508 sites are not flagged, but only 153 of these 310 sites show absolute stationarity behavior (category 1), and the rest exhibit some form of nonstationary.

From Table 1 we observe the following.

1. If a site is flagged and its low flow series has a trend, the flags are mostly for regulation of partial regulation; sites with increasing trends are more likely to be flagged as regulated.

2. If a site is flagged and it exhibits a step change, the flag is mostly associated with regulation, or possibly urbanization;

3. If a site is in category 5 (not considered further due to significant autocorrelation), it may be flagged as regulated.

4. If a site shows no trend but is still flagged, the flag relates to regulation. This suggests that the impact of the flagged change was either minimal or good management practices have been put in place. The majority of these sites are located in the upper Mid-Atlantic in the states of New York, New Jersey, and Virginia.

We also applied the algorithm to the HCDN-2009 sites within the domain, to confirm that the algorithm can identify sites that have been independently determined as unaffected by human influences. We found that 82 and $86 \%$ of these sites were placed in category 1 (stationary) for Q7 and Q30, respectively, with most of the remaining sites in category 3 (in- 

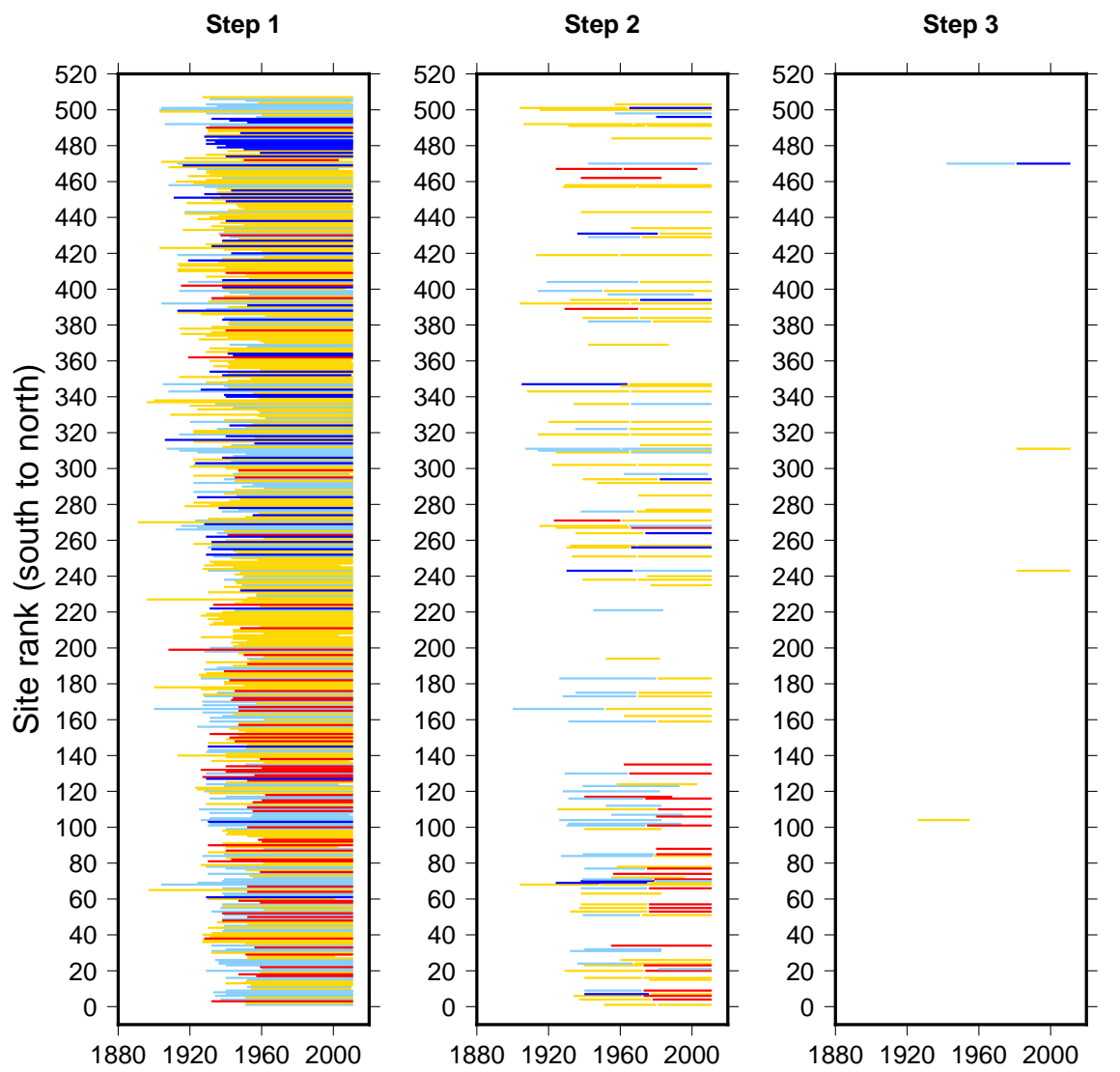

Step change (split)

Decreasing trend

Increasing trend

Not significant trend

Figure 3. Range of years for each site that contain a step change, show a trend, or are stationary, for each step of the decomposition algorithm.

creasing trend; 9 and $8 \%$ ) or category 6 (autocorrelated; $5 \%$ and $4 \%$ ).

\subsection{Variability in year of abrupt change}

For sites that were identified by the Pettitt test as having an abrupt change, Fig. 5a, b shows the variability of the year of change for Q7 and Q30. Most of the changes occurred between 1962 and 1986, and as discussed above, most of these are flagged as having regulation. The spatial distribution of changes indicates that stream regulation began in the northeast before spreading to the southeast. The Pettit test tends to identify significant changes away from the either ends of the time series, and so may not identify changes in the earlier or later part of the record. However, earlier or later step changes are identified in the second recursion of the decomposition algorithm.

We further examined the consistency of the change year among the Qn series, with the expectation that abrupt changes would be identified for the same year across all or most Qn time series. Figure 5c shows the spatial distribution and the number of sites with a consistent year of change between Q7 and Q30. Out of 111 sites whose Q7 time series were identified as having a step change by the Pettitt test, more than half (61) showed the same change year for as the Q30 series. Although we have identified the change year for all Qn, the results for Q7 may be the most appropriate for identifying a change since the data are close to the original values, but are less affected by measurement errors than Q1 (WMO, 2008).

\section{Variability and trends in low flows and timing}

\subsection{Trends in low flows}

We identified a time period (1951-2005) common to all sites for which they have useable data, and calculated statistics of Qn, including the trend, and the consistency of trends among Qn values. The MK trends for Qn for the sites that were categorized as 1, 2, or 3 by the decomposition algorithm and are shown in Fig. 6a for Q7 and Q30. Sites with lower trend magnitudes tend to become non-significant $(\mathrm{MK}=0)$ as we move from Q1 to Q90 (not shown). Overall, the northeastern sites show increasing trends in low flows and the southeastern sites show decreasing trends. 


\section{$Q_{7}$ low flow categories, no USGS flags}

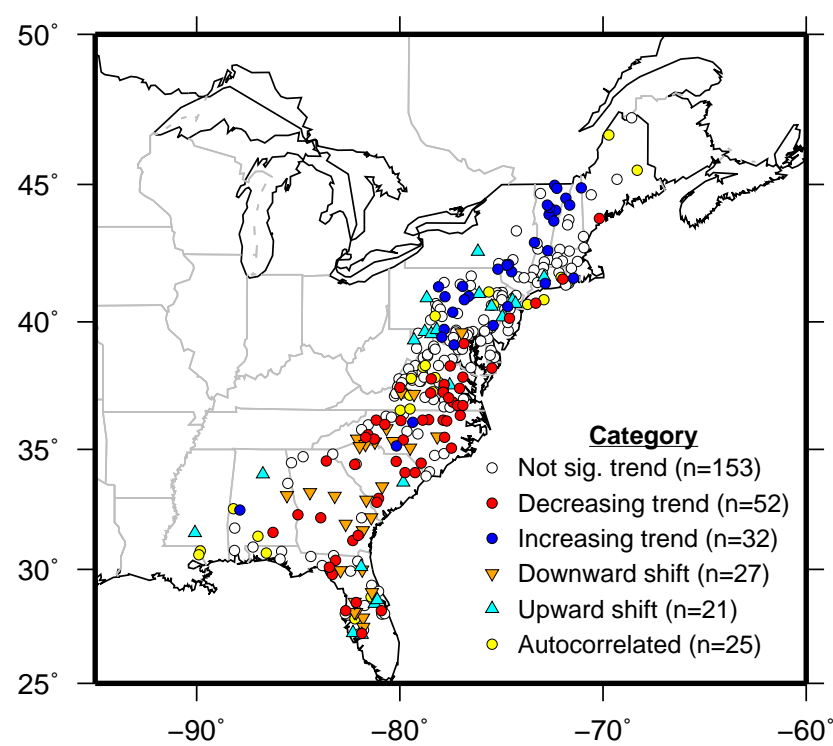

Figure 4. Categorization of nonstationarity of sites for Q7 with no USGS flags from the first step of the decomposition algorithm.

A summary of the consistency of trends between Q7 and Q30 low flows is shown in Fig. 6c. 336 sites (88\% of the sites) have the same trend, such that the Q7 and Q30 series are all increasing, decreasing, or not changing. 162 sites (32\%) agree on the sign of trend for three out of four of the Qn trends, and 87 sites (17\%) agree for two out of four of the Qn trends. Overall, the consistency in trends among the Qn series is generally uniformly distributed across the domain.

Figure 7 (top left) shows the spatial pattern of the MK trend test values for Q7 for all sites (without testing for step changes or autocorrelation), and when we only consider sites without step changes (top right). In both cases, the pattern of increasing trend in low flows in the northeast and a decreasing trend in the southeast is apparent. However, ignoring the effect of autocorrelation may give rise to misleading results by showing a denser pattern of significant trends. The bottom left panel shows the results removing sites with step changes and pre-whitening the data for the remaining sites. The bottom right panel show the trends when sites that have USGS flags are also excluded, e.g., for sites without documented anthropogenic impacts. The drivers of trends at these sites are therefore likely related to climate variability/change and/or land use change, rather than management of, or influence on, flows.

\subsection{Variability in low flow timing}

Figure 8 summarizes the distribution of the onset of the low flow season for Q7, for the primary season (top panels) and the second season (bottom panels). The left panels show the onset month of the season and the right panels show the prob- ability of the onset season in that month. If the onset time of the low flow season for a site occurs 70 to $100 \%$ in a specific month, that site is assumed to have only one low flow season. For Q7, 353 sites out of 395 (almost 90\%) sites have a single low flow season, and the onset of the season changes from north to south. Most of the sites north of North Carolina have low flow seasons starting in July, which is generally driven by the slight decline in precipitation during the fall as well as the increased evaporation during the summer (Small et al., 2006). In Florida the season starts in April-May. For coastal sites, the season starts earlier (mostly in June), and for sites in the southwestern part of the domain, the season starts mostly in September-October.

The sites with two low flow seasons are mostly in Florida, and along the coastline of Georgia, South and North Carolina, New York, New Jersey, and Maine, and their second season occurs mostly in fall. For New York, New Jersey, and some sites along the western coastline of Florida, the second low flow season mostly starts in November and December. Sites near the Gulf of Mexico and some sites in North Carolina have second low flow seasons starting in April. The second low flow season for the far northeastern sites begins in December or January and can be related to freezing conditions that may store water as snow and river ice.

\subsection{Changes in low flow timing}

To determine whether low flow timing has changed over time, we examined sites with one low flow season as defined as $70 \%$ of low flow occurrences in the same season, again for the common time period of 1951-2005. Analysis of changes in timing irrespective of the season (not shown) did not show evidence of shifts in timing from one season to another. For Q7, for example, 47 sites out of the total 508 were removed because their low flow season occurs less than $70 \%$ of the time in one season. Out of the remaining 467 sites, 20 sites showed a decreasing (earlier) trend in timing and were mostly in Pennsylvania and the Carolinas (Fig. 9) and 14 showed an increasing (later) trend with most of these in the northeast. The MK test for Q30 timings showed mainly decreasing (earlier) trends (26 sites), with most overlap with the Q7 results in Pennsylvania. These sites have low flow seasons starting in July, and half of them are regulated or partially regulated. Only a few sites were identified by the Pettitt test (5\% significance) to have a significant step change in either direction.

The tendency for low flows (Q7 and Q30) to occur earlier in the season in recent years may be because of a shift of low precipitation from the late to mid summer, but given the small number of sites with significant trends and their low spatial coherence, this is speculative. Although the sites in Pennsylvania did not show a trend in low flow volumes, the overall trend for the northeast is an increasing trend in low flow volumes suggesting that early summer low precipitation might also be increasing. More investigation is required 
(a) Year of step change for $Q_{7}$

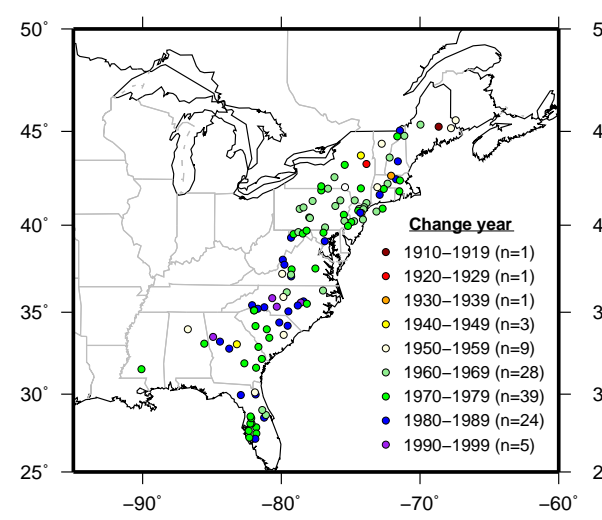

(b) Year of step change for $Q_{30}$

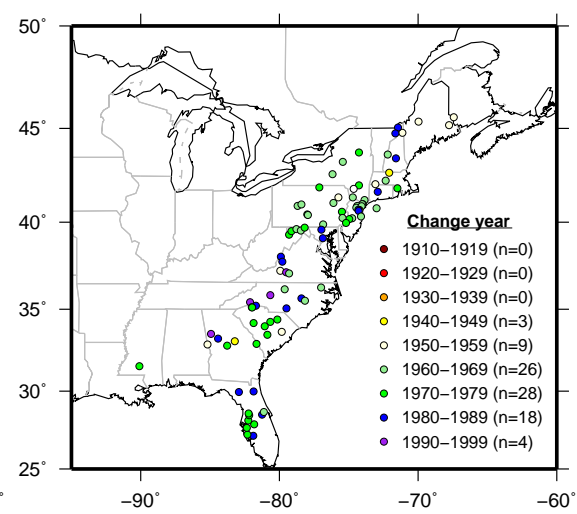

(c) Agreement of year between $Q_{7}$ and $Q_{30}$

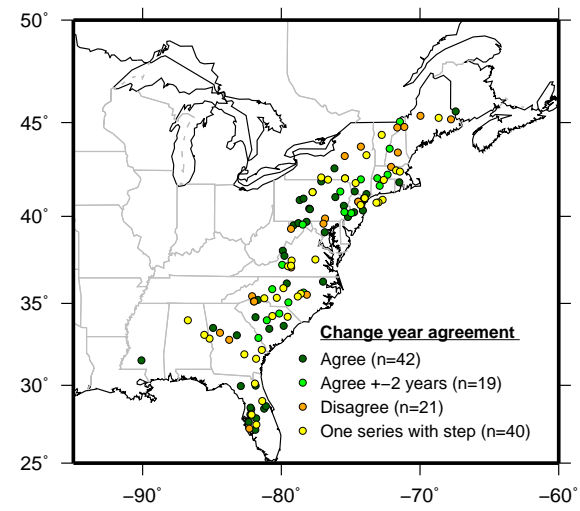

Figure 5. Year of step change for (a) Q7 and (b) Q30. (c) Agreement in year of step change between Q7 and Q30 time series.

to confirm whether low precipitation is happening earlier in summer, for example during May and June, and whether the amount is increasing.

\section{Discussion and conclusions}

\subsection{Potential drivers of trends in low flows}

We found spatially coherent patterns of increases in low flows in the northeast and decreases in the southeast, which was robust to the presence of USGS flags and autocorrelation in the time series, despite the smaller number of sites. The pattern of increasing low flows in the northeast is consistent with regional-scale studies (e.g., Hodgkins and Dudley, 2011) and is consistent with the increases in 7-day low flows and fall precipitation shown in Small et al. (2006) that focused on a smaller set of sites across the eastern US from the HCDN. Several other studies (e.g., Douglas et al., 2000; McCabe and Wolock, 2002; Hayhoe et al., 2007; Andreadis and Lettenmaier, 2006) have identified an overall increasing trend in precipitation over the past 50 years, and a decreasing pattern in soil moisture drought over the much of the US including the northeast (Andreadis and Lettenmaier, 2006). Therefore, an increase in low flow volumes in the northeast is consistent with the overall shift to wetter conditions. The generally decreasing trends in the southeast are also consistent with the results from Small et al. (2006) and Lins and Slack (1999), which is despite an overall increase in precipitation in the region.

To understand the potential drivers of these trends more comprehensively, Fig. 10 shows the Q7 trend magnitude and the antecedent precipitation for the previous 180 days. This period was chosen as it provides the highest correlation with low flow volumes (Kam et al., 2015), although the results with 150 and 90 days are similar. The precipitation data are taken from the long-term precipitation data set of Livneh et al. (2013) and are averaged over the basin corresponding to each site. The similarity between the trends in low flows and antecedent precipitation is striking, with a clear increasing trend in the north and decrease in the south, although many of the trends are not statistically significant.

The main disparity is in coastal plains of eastern Virginia, Maryland and northwards to Maine, where Q7 low flows have decreased but antecedent precipitation is increas- 
(a) Trend of $Q_{7}$

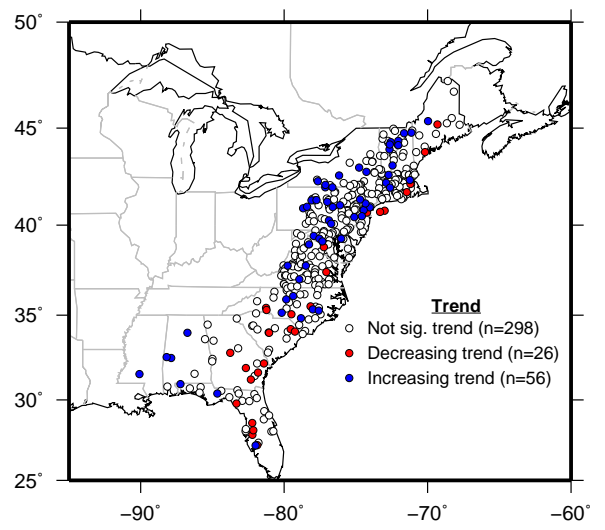

(b) Trend of $Q_{30}$

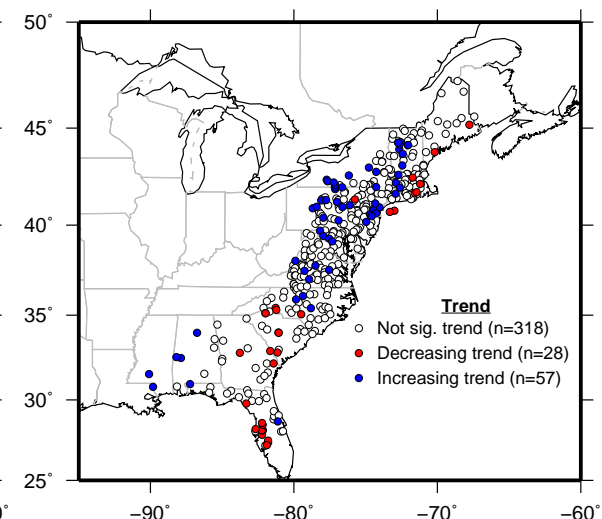

(c) Agreement of trends in $Q_{7}$ and $Q_{30}$

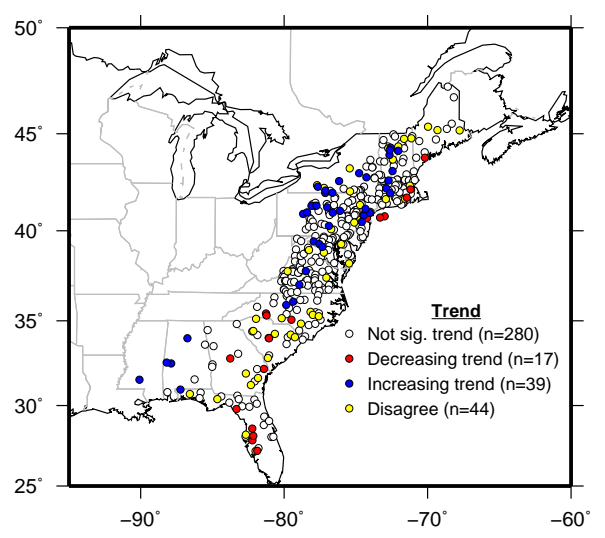

Figure 6. Trends in (a) Q7 and (b) Q30 for 1951-2005 and (c) their agreement.

ing (both often statistically significant). The reason for this is unclear, but groundwater is likely playing a role across the coastal plain aquifer of the mid-Atlantic states and up into New England (Dudley and Hodgkins, 2013) either via changes in recharge or indirectly through anthropogenic impacts. Groundwater pumping has reduced levels in the northern Atlantic Coastal Plain aquifer system by tens of meters (e.g., Konikow, 2013, USGS, 2006) and has likely reduced discharge to streams in the northeast (e.g., Pucci and Pope, 1995; Brutsaert, 2010; Barlow and Leake, 2012). Similarly, overuse of groundwater resources in the southeast (Konikow, 2013) may be contributing to decreases in low flows across the region (e.g., Bosch et al., 2003; Opsahl et al., 2007; Brutsaert, 2010).

Increases in evaporation (Walter et al., 2004; Huntington and Billmire, 2014) may have also led to declines in groundwater recharge and streamflow (Hodgkins and Dudley, 2011), and potentially cancelled out the overall increases in precipitation across much of the US (Andreadis and Lettenmaier, 2006). Figure 10 also shows an estimate of the trend in late summer/early fall potential evaporation based on the NLDAS2 data set of Xia et al. (2012). Potential evaporation has increased over the eastern US, with statistically significant trends over much of the mid-Atlantic states and the southeast. This suggests that increasing atmospheric demand in the southeast may have exacerbated declines in low flows, and this may have offset increasing precipitation somewhat in the northeast. Changes in land use may also explain trends in both regions, whereby land abandonment in the northeast and forest harvesting and urban development in the southeast may have contributed to the respective trends in each region (Cho et al., 2009; Payne et al., 2005; USGS, 2012), although attribution is difficult.

The analysis of trends in timing of low flows showed one cluster of sites with a trend to earlier timing. These sites are mostly in central and western Pennsylvania, and central southern New York. The reasons for the changes are unclear, but may be related to regulation and possibly a shift in the low precipitation season to earlier in the summer. The timing of low flows in the other parts of the domain has not changed based on a $5 \%$ significance level. 
(a) Trend $Q_{7}$, all sites

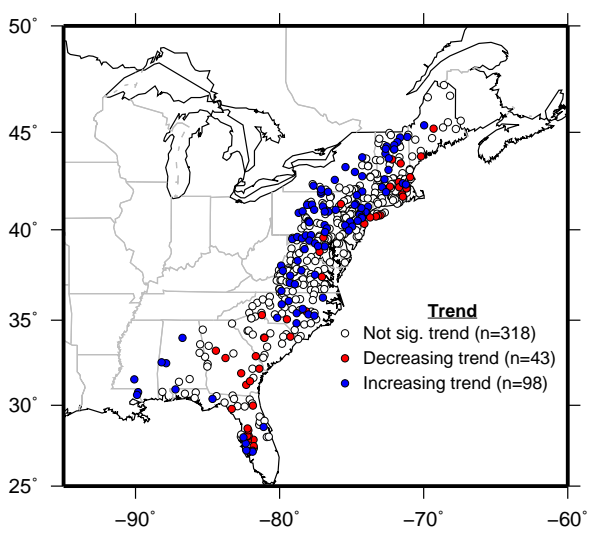

(c) Trend $Q_{7}$, all sites, no step changes, pre-whitened

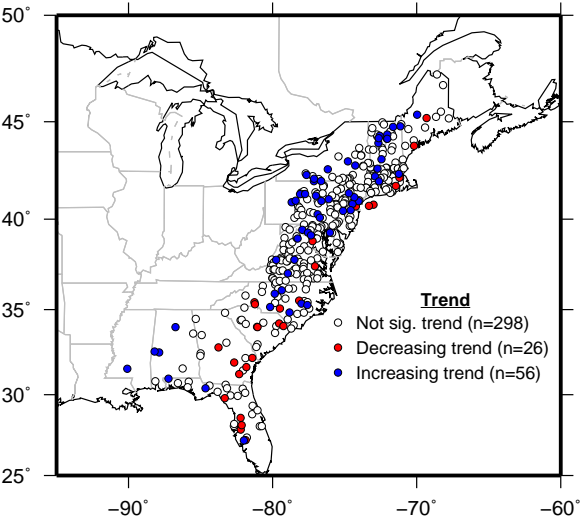

(b) Trend $Q_{7}$, all sites, no step changes

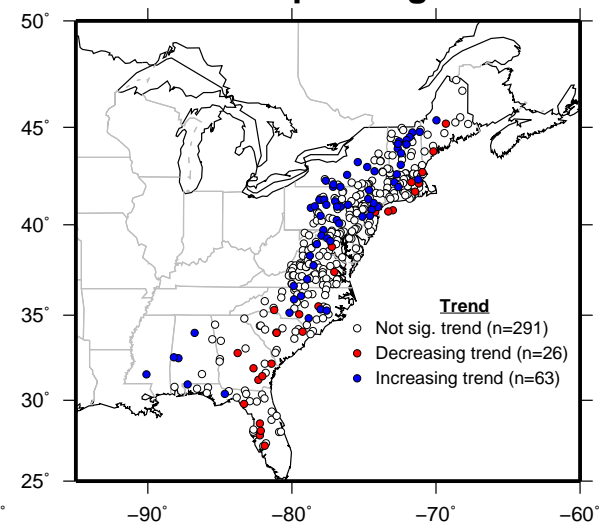

(d) Trend $Q_{7}$, all sites, no step changes, pre-whitened, no flags

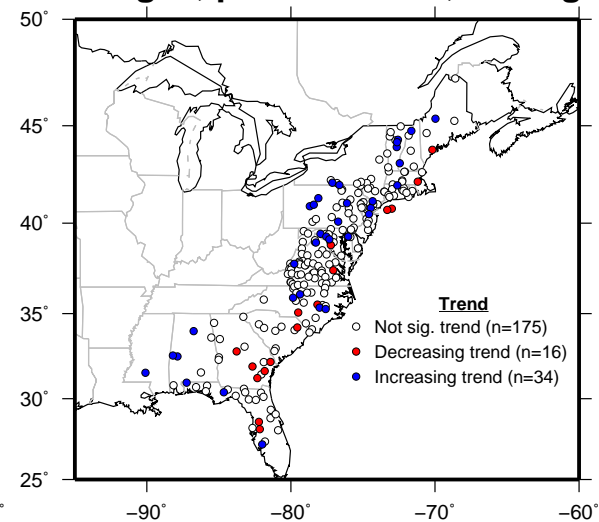

Figure 7. Trends in Q7 for 1951-2005 for (a) all sites, (b) excluding sites with step changes or overall autocorrelation, (c) as (b) but with pre-whitened data, and (d) as (b) but without USGS flags.

\subsection{Conclusions}

This study has examined the presence of nonstationarity in low flows across the eastern US in terms of volumes and timing. We focused on the full period of available data at each site to identify abrupt shifts that may be associated with management, in particular dam construction, and gradual trends that may be an impact of climate change, land use change or surface water/groundwater withdrawals. A decomposition algorithm was used to identify useable sub-series of the data that could then be further analyzed for trends. Comparison with USGS site flags indicates that the majority of sites with identified step changes and increasing trends are noted to be regulated in some way, and some are documented as having undergone urbanization. For sites with decreasing and increasing trends, about one sixth and one half, respectively, have USGS flags and these are almost all for regulation. Furthermore, about one third of sites with no trend are also flagged as being regulated or partially regulated. Our approach is therefore generally capable of identifying sites with documented regulation, and confirmed by the evaluation of the HCDN-2009 sites, but regulation does not always manifest in a detectable change in the low flow time series. This may be because the documented regulation or other change did not have an impact or that the signal is small compared to the variability in the time series. This is particularly the case for higher low flow metrics such as Q90, for which the regulation is generally less detectable. For sites with documented regulation but no detectable signal, the fact that the USGS flags relate to high flows rather than low flows may help explain this, or that the sites are well managed in terms of low flows. For example, flows are often artificially elevated above the natural levels of low flow to create "antidroughts" to manage the restoration of river systems (Bunn et al., 2006).

Several outstanding questions remain, most importantly what are the low flow generating mechanisms across the eastern US and what are the drivers of long-term changes in the volumes and timing. Potential mechanisms include but are not limited to changes in antecedent precipitation and tele- 

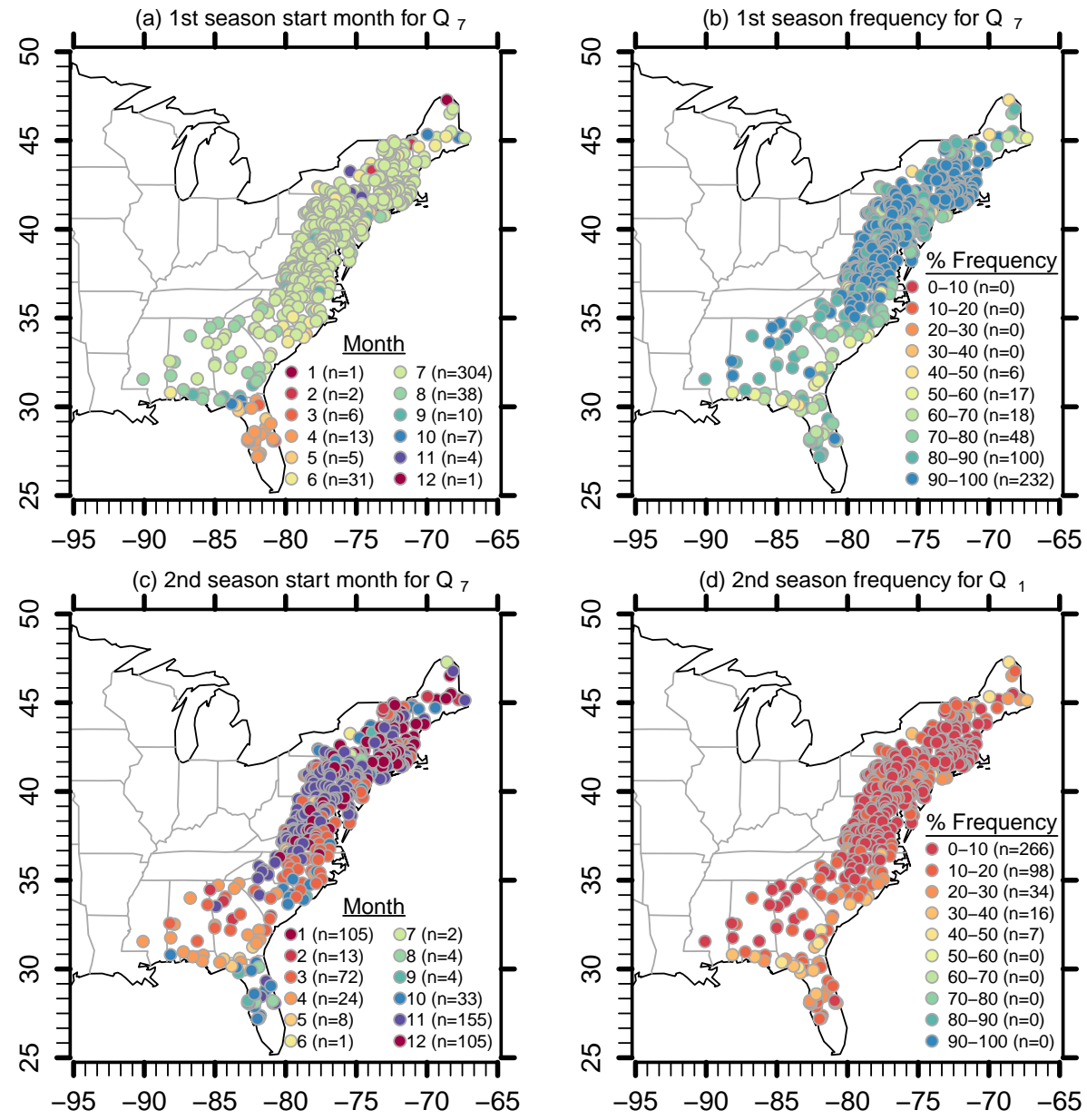

Figure 8. Primary and secondary seasons of occurrence of Q7 low flows and their frequencies.

(a) $Q_{7}$ timing categories

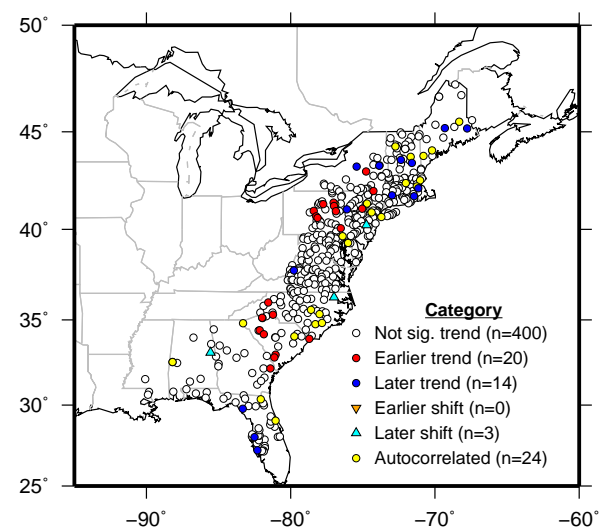

(b) $Q_{30}$ timing categories

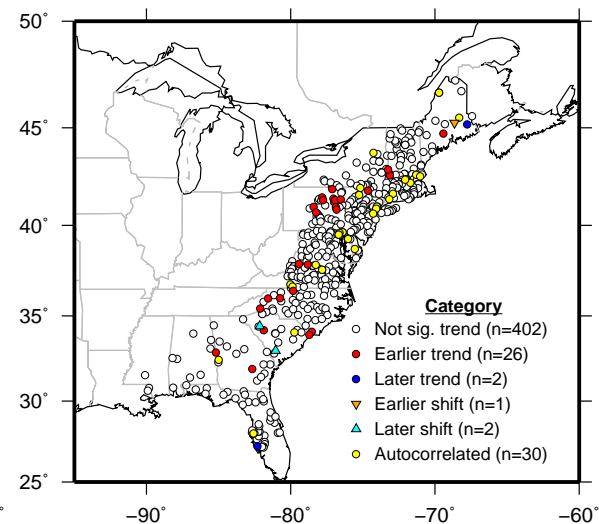

Figure 9. Categorization of nonstationarity of sites for timing of (a) Q7 and (b) Q30.

connections with large-scale climate (e.g., the North Atlantic Oscillation; Kam et al., 2015), land use change, surface and groundwater abstraction, and streamflow regulation. The results of this study suggest that low flow variability in the east- ern US is driven by a mixture of climatic and anthropogenic effects, with suggestions that changes in climate have played a role in both the northeast and southeast. However, definitive attribution will require detailed analysis of these compet- 
(a) $Q_{7}$ low flows

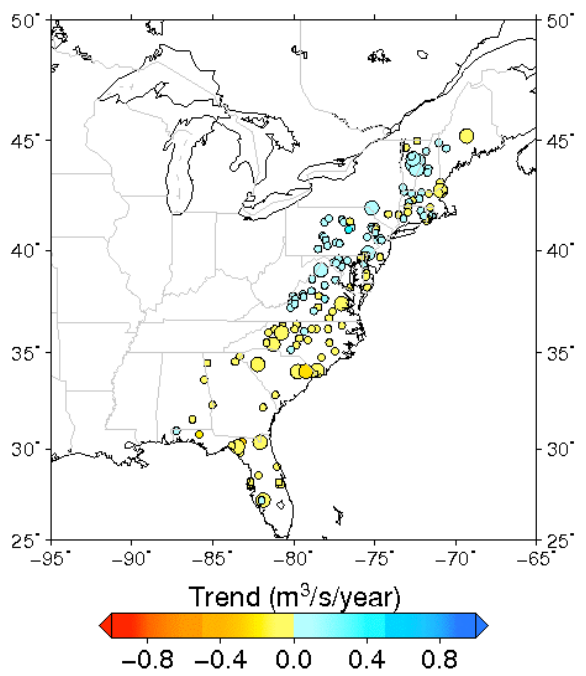

(c) JAS PE

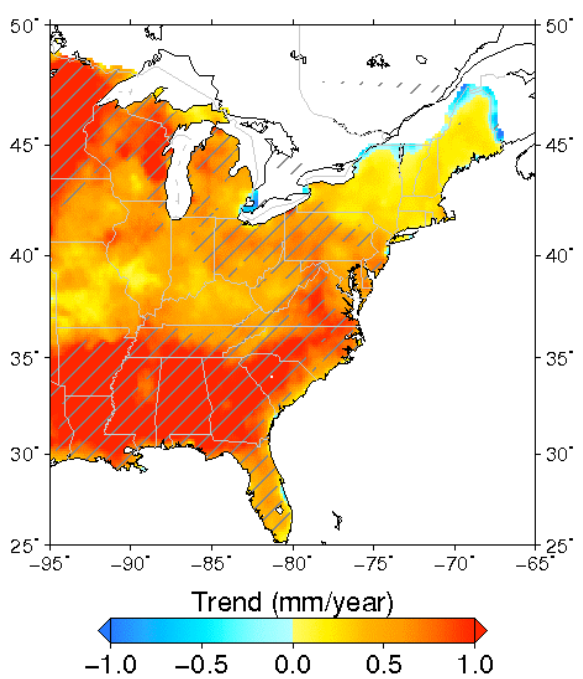

(b) 180-day antecedent precipitation

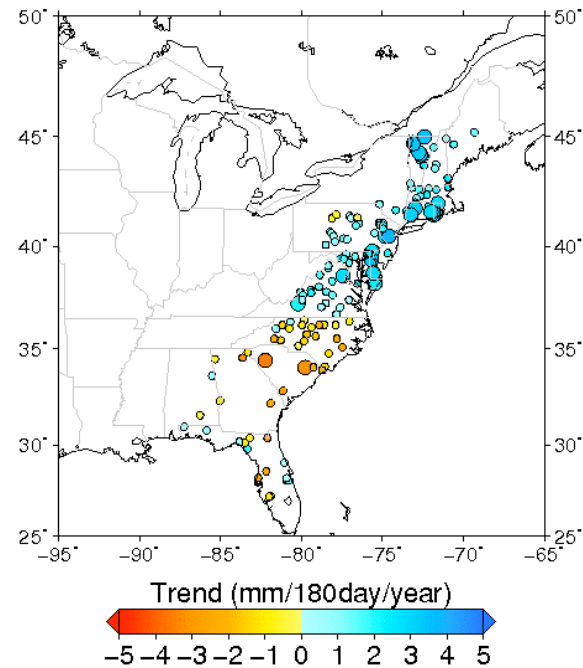

. $0^{-1}$

Figure 10. (a) Trend in Q7 low flows for 1951-2005 for the warm season. (b) Corresponding trend in 180-day antecedent precipitation. For (a) and (b), trends that are statistically significant at the 0.05 level are shown in large symbols. (c) Trend in July-August-September (JAS) potential evaporation for 1979-2012. Statistically significant trends are shown by hatching.

ing factors and possibly carefully crafted modeling studies. In parallel with calls for more rigorous efforts at attributing changes in flood time series (Merz et al., 2012), increased effort is also needed for understanding and attributing changes in low flows. Several new approaches have been put forward recently that show promise for detecting and attributing changes in hydrological time series, including extremes, based on multiple working hypotheses (Harrigan et al., 2014) and complex statistical modeling (Prosdocimi et al., 2015).

The results of this study can help in understanding changes in low flows across the eastern US, and the impact of anthropogenic and natural changes. It can therefore provide in- formation for water management, and restoration of stream flows and aquatic habitats. Although we do not claim to make a definitive judgment on whether low flows at a particular site are influenced by human activities or are completely free of influences because of the complexities of low flow generation, our approach shows promise for systematically identifying sites for further investigation, especially where supporting information (such as site notes) are available to support the statistical results. Our approach may be especially useful for exploring large-scale, climate-driven changes in the low flow regime where pooling of results across sites increases confidence in the robustness of any identified changes. The 
methods are readily transferable to other parts of the US and globally, given long enough time series of daily streamflow data, although further work is required to understand their universal application.

Author contributions. S. Sadri and J. Sheffield conceived the study. S. Sadri performed the analysis with help from J. Kam. S. Sadri prepared the manuscript with contributions from the other authors.

Acknowledgements. This work was supported by the USGS (G11AP20215) and NOAA (NA14OAR4310130 and NA14OAR4310218).

Edited by: K. Stahl

\section{References}

Acreman, M. C., Adams, B., and Connorton, B.: Does groundwater abstraction cause degradation of rivers and wetlands?, Water Environ. J., 14, 200-206, 2000.

Andreadis, K. M. and Lettenmaier, D. P.: Trends in 20th century drought over the continental united state, Geophys. Res. Lett., 33, 1-4, 2006.

Averyt, K., Meldrum, J., Caldwell, P., Sun, G., McNulty, S., HuberLee, A., and Madden, N.: Sectoral contributions to surface water stress in the coterminous United States, Environ. Res. Lett., 8, 035046, 9 pp., doi:10.1088/1748-9326/8/3/035046, 2013.

Barlow, P. M., and Leake, S. A.: Streamflow depletion by wells Understanding and managing the effects of groundwater pumping on streamflow, US Geological Survey Circular, 1376, 84 pp., 2012.

Bosch, D. D., Lowrance, R. R., Sheridan, J. M., and Williams, R. G.: Ground water storage effect on streamflow for a Southeastern Coastal Plain watershed, Ground Water, 41, 903-912. doi:10.1111/j.1745-6584.2003.tb02433.x, 2003.

Bradford, M. and Heinonen, J.: Low flows, instream flow needs and fish ecology in small streams, Canad. Water Resour. J., 33, 165180, 2008.

Brandes, D., Cavallo, G. J., and Nilson, M. L.: Base flow trends in urbanizing watersheds of the delaware river basin, $\mathrm{J}$. Am. Water Resour. Assoc., 41, 1377-1391, doi:10.1111/j.17521688.2005.tb03806.x, 2005.

Brown, T. C., Foti, R., and Ramirez, J. A.: Projected freshwater withdrawals in the United States under a changing climate. Water Resour. Res., 49, 1259-1276, doi:10.1002/wrcr.20076, 2013.

Brutsaert, W.: Annual drought flow and groundwater storage trends in the eastern half of the United States during the past two-third century, Theor. Appl. Climatol., 100, 93-103, 2010.

Bunn, S. E., Thoms, M. C., Hamilton, S. K., and Capond, S. J.: Flow variability in dryland rivers: boom, bust and the bits in between, River Res. Appl., 22, 179-186, 2006.

Burakowski, E. A., Wake, C. P., Braswell, B., and Brown, D. P.: Trends in wintertime climate in the northeastern United States: 1965-2005, J. Geophys. Res., 113, D20114, doi:10.1029/2008JD009870, 2008.
Cho, J., Barone, V. A., and Mostaghimi, S.: Simulation of land use impacts on groundwater levels and streamflow in a Virginia watershed, Agr. Water Manage., 96, 1-11, 2009.

Cohn, T. A. and Lins, H. F.: Nature's style: Naturally trendy. Geophys. Res. Lett., 32, L23402, doi:10.1029/2005GL024476, 2005.

Colby, F. P.: Mesoscale snow bands in an ocean-effect snowstorm. Tech. rep., University of Massachusetts Lowell, Lowell, MA 01854, 2008.

Daniel, C. and Dahlen, P.: Preliminary hydrogeologic assessment and study plan for a regional ground-water resource investigation of the Blue Ridge and Piedmont Provinces of North Carolina, Investigations Report 02-4105, USGS, 2002.

Deitch, M. J., Kondolf, G. M., and Merenlender, A. M.: Hydrologic impacts of small-scale instream diversions for frost and heat protection in the California wine country, River Res. Appl., 25, 118134, 2009.

Douglas, E. M., Vogel, R. M., and Kroll, C. N.: Trends in floods and low flows in the United States: impact of spatial correlation, J. Hydrology, 240, 90-105, 2000.

Dudley, R. W. and Hodgkins, G. A.: Historical groundwater trends in northern New England and relations with streamflow and climatic variables, J. Am. Water Resour. Assoc., 49, 1198-1212, 2013.

EPA Climate Change Division: Precipitation and storm changes, available at: www.epa.gov/climatechange/science/indicators/ weather-climate/index.html (last access: December 2014), 2008.

Giuntoli, I., Renard, B., Vidal, J.-P., and Bard, A.: Low flows in France and their relationship to large-scale climate indices, J. Hydrology, 482, 105-118, 2013.

Gurka, J. J., Auciello, E. P., Gigi, A. F., Waldstreicher, J. S., Keeter, K. K., Businger, S., and Lee, L. G.: Winter weather forecasting throughout the eastern United States. Part II: An operational perspective of cyclogenesis, Am. Meteorol., 10, 21-41, 1995.

Harrigan, S., Murphy, C., Hall, J., Wilby, R. L., and Sweeney, J.: Attribution of detected changes in streamflow using multiple working hypotheses, Hydrol. Earth Syst. Sci., 18, 1935-1952, doi:10.5194/hess-18-1935-2014, 2014.

Hayhoe, K., Wake, C. P., Huntington, T. G., Luo, L., Schwartz, M. D., Sheffield, J., Wood, E., Anderson, B., Bradbury, J., Degaetano, A., Troy, T. J., and Wolfe, D.: Past and future changes in climate and hydrological indicators in the US Northeast, Clim. Dynam., 28, 381-407, 2007.

Hodgkins, G. A. and Dudley, R. W.: Historical summer base flow and stormflow trends for New England rivers, Water Resour Res., 47, W07528, doi:10.1029/2010WR009109, 2011.

Hodgkins, G. A., Dudley, R. W., and Huntington, T. G.: Changes in the number and timing of days of ice-affected flow on northern New England rivers, Clim. Change, 71, 319-340, doi:10.1007/s10584-005-5926-z, 2005.

Huntington, T. G. and Billmire, M.: Trends in precipitation, runoff, and evapotranspiration for rivers draining to the Gulf of Maine in the United Statesm, J. Hydrometeorol., 15, 726-743, 2014.

Kam, J., Sheffield, J., Yuan, X., and Wood, E. F.: The influence of Atlantic tropical cyclones on drought over the Eastern U.S (1980-2007), J. Climate, 26, 3067-3086, doi:10.1175/JCLI-D12-00244.1, 2013.

Kam, J. and Sheffield, J.: Changes in the low flow regime over the Eastern United States (1962-2011): Variability, trends, and attri- 
butions, Climatic Change, doi:10. 1007/s10584-015-1574-0, in press, 2015.

Karl, T. R. and Knight, R. W.: Secular trends of precipitation amount, frequency, and intensity in the United States, B. Am. Meteor. Soc., 79, 231-241, 1998.

Kendall, M. G.: Rank Correlation Methods, Charles Griffin, 202 pp., 1975.

Kendall, M., Stuart, A., and Ord J. K.: The Advanced Theory of Statistics, Vol. 3, Design and Analysis, and Time Series, 4th Edn., Oxford Univ. Press, New York, 780 pp., 1983.

Konikow, L. F.: Groundwater depletion in the United States (19002008): U.S. Geological Survey Scientific Investigations Report 2013-5079, 63 pp., http://pubs.usgs.gov/sir/2013/5079, 2013.

Koutsoyiannis, D.: Hurst-Kolmogorov dynamics and uncertainty, J. Am. Water Resour. Assoc., 47, 481-495, 2011.

Kroll, C., Luz, J., Allen, B., and Vogel, R. M.: Developing a watershed characterisitics database to improve low streamflow prediction, J. Hydrol. Eng., 9, 116-125, 2004.

Kroll, C. N. and Vogel, R. M.: Probability distribution of low streamflow series in the United States, J. Hydrol. Eng., 7, 137146, 2002.

Kumar S, Merwade, V., Kam, J., and Thurner, K.: Streamflow trends in Indiana: effects of long term persistence, precipitation and subsurface drains, J. Hydrol., 374, 171-183, 2009.

Kustu, M. D., Fan, Y., and Robock, A.: Large-scale water cycle perturbation due to irrigation pumping in the US High Plains: A synthesis of observed streamflow changes, J. Hydrol., 390, 222244, doi:10.1016/j.jhydrol.2010.06.045, 2010.

Lins, H. and Slack, J. R.: Streamow trends in the United States, Geophys. Res. Lett., 26, 227-230, 1999.

Lins, H. F.: USGS Hydro-Climatic Data Network 2009 (HCDN2009): U.S. Geological Survey Fact Sheet 2012-3047, 4 pp., available at: http://pubs.usgs.gov/fs/2012/3047/, 2012.

Lins, H. F. and Cohn, T. A.: Stationarity: Wanted Dead or Alive?, J. Am. Water Resour. Assoc., 47, 475-480, doi:10.1111/j.17521688.2011.00542.x, 2011.

Livneh, B., Rosenberg, E. A., Lin, C., Nijssen, B., Mishra, V., Andreadis, K. M., Maurer, E. P., and Lettenmaier, D. P.: A long-term hydrologically based dataset of land surface fluxes and states for the conterminous United States: Update and extensions, J. Climate, 26, 9384-9392, 2013.

Ljung, G. and Box, G.: On a Measure of Lack of Fit in Time Series Models, Biometrika, 65, 297-303, 1978.

Mann, H. B.: Nonparametric tests against trend, Econometrica, 13, 245-259, 1945.

Mauget, S. A.: Multidecadal regime shifts in U.S. streamflow, precipitation, and temperature at the end of the twentieth century, J. Climate, 16, 3905-3916, 2003.

McCabe, G. J. and Wolock, D. M.: A step increase in streamflow in the conterminous United States, Geophys. Res. Lett., 29, 1-4, 2002.

McCabe, G. J. and Wolock, D. M.: Joint Variability of Global Runoff and Global Sea Surface Temperatures, J. Hydrometeorol., 9, 816-824, doi:10.1175/2008JHM943.1, 2008.

Merz, B., Vorogushyn, S., Uhlemann, S., Delgado, J., and Hundecha, Y.: HESS Opinions "More efforts and scientific rigour are needed to attribute trends in flood time series", Hydrol. Earth Syst. Sci., 16, 1379-1387, doi:10.5194/hess-16-13792012, 2012.
Opsahl, S. P., Chapal, S. E., Hicks, D. W., and Wheeler, C. K.: Evaluation of ground-water and surface-water exchanges using streamflow difference analyses, J. Am. Water Resour. Assoc., 43, 1132-1141, doi:10.1111/j.1752-1688.2007.00093.x, 2007.

Payne, D. F., Rumman, M. A., and Clarke, J. S.: Simulation of ground-water flow in coastal Georgia and adjacent parts of South Carolina and Florida - Predevelopment, 1980, and 2000: U.S. Geological Survey, Scientific Investigations Report 2005-5089, 91 pp., 2005.

Pettitt, A. N.: A non-parametric approach to the change-point problem, Appl. Stat., 28, 126-135, 1979.

Poff, N. L., Allan, J. D., Bain, M. B., Karr, J. R., Prestegaard, K. L., Richter, B. D., Sparks, R. E., and Stromberg, J. C.: The natural flow regime: a paradigm for river conservation and restoration, Bioscience, 47, 769-784, 1997.

Prosdocimi, I., Kjeldsen, T. R., and Miller, J. D.: Detection and attribution of urbanization effect on flood extremes using nonstationary flood-frequency models, Water Resour. Res., 51, 4244-4262, doi:10.1002/2015WR017065, 2015.

Pucci, A. A. and Pope, D. A.: Simulated effects of development on regional ground-water/surface-water interactions in the northern Coastal Plain of New Jersey, J. Hydrology, 167, 241-262, 1995.

Rolls, R. J., Leigh, C., and Sheldon, F.: Mechanistic effects of lowflow hydrology on riverine ecosystems: ecological principles and consequences of alteration, Freshw. Sci., 31, 1163-1186, 2012.

Ruppert, D.: Statistics and data analysis for financial engineering, Springer Texts in Statistics, Springer, 2011.

Serinaldi, F. and Kilsby, C. G.: Stationarity is undead: Uncertainty dominates the distribution of extremes, Adv. Water Resour., 77, 17-36, 2015.

Smakhtin, V. U.: Low flow hydrology: a review, J. Hydrology, 240, 147-186, 2001.

Small, D., Islam, S., and Vogel, R. M.: Trends in precipitation and streamflow in the eastern U.S.: Paradox or preception?, Geophys. Res. Lett., 33, 1-4, 2006.

Tallaksen, T. and Van Lanen, H. A.: Hydrological drought, processes and estimation methods for streamflow and groundwater, 48, 580 pp., Elsevier Sci., 2004.

Thomas, B.: Trends in Streamflow of the San Pedro River, Southeastern Arizona, US Geological Survey Fact Sheet 2006-3004, 4 pp., available at: http://pubs.usgs.gov/fs/2006/3004/ (last access: December 2014), 2006.

US Senate: Federal Water Pollution Control Act, available at: www. epw.senate.gov/water.pdf (last access: December 2014), 2002.

USGS: Sustainability of the Ground-Water Resources in the Atlantic Coastal Plain of Maryland, USGS Fact Sheet, 2006-3009, 2 pp., 2006.

USGS: Groundwater atlas of the United States, available at: www. pubs.usgs.gov/ha/ha730/ (last access: December 2014), 2009.

USGS: Land cover change in the eastern United States, available at: www.landcovertrends.usgs.gov/east/regionalSummary.html (last access: December 2014), 2012.

USGS: Groundwater depletion in the United States (1900-2008). Scientific Investigation Report 2013-5079, US Department of the Interior, US Geological Survey, Reston, Virginia, 2013.

USGS: National Water Information System data available on the World Wide Web (Water Data for the Nation), available at: http: //waterdata.usgs.gov/nwis/, last access: December 2014. 
Villarini, G., Smith, J. A., Serinaldi, F., Bales, J., Bates, P. D., and Krajewski, W. F.: Flood frequency analysis for nonstationary annual peak records in an urban drainage basin, Adv. Water Resour., 32, 1255-1266, 2009.

Walker, K. F. and Thoms, M. C.: Environmental effects of flow regulation on the lower river Murray, Australia, Regul. Rivers: Res. Mgmt., 8, 103-119, doi:10.1002/rrr.3450080114, 1993.

Walter, M. T., Wilks, D. S., Parlange, J.-Y., and Schneider, R. L.: Increasing evapotranspiration from the conterminous United States, J. Hydrometeor., 5, 405-408, doi:10.1175/15257541(2004)005<0405:IEFTCU>2.0.CO;2, 2004.

WMO: Manual on low-flow estimation and prediction. Operational Hydrology Report 30, WMO-N 1029, Geneva, Switzerland, 2008.
Xia, Y., Mitchell, K., Ek, M., Sheffield, J., Cosgrove, B., Wood, E., Luo, L., Alonge, C., Wei, H., Meng, J., Livneh, B., Lettenmaier, D., Koren, V., Duan,Q., Mo, K., Fan, Y., and Mocko, D.: Continental-Scale Water and Energy Flux Analysis and Validation for the North-American Land Data Assimilation System Project Phase 2 (NLDAS-2), Part 1: Intercomparison and Application of Model Products, J. Geophys. Res., 117, D03110, doi:10.1029/2011JD016051, 2012.

Yue, S. and Wang, C. Y.: Applicability of prewhitening to eliminate the influence of serial correlation on the Mann-Kendall test, Water Resour. Res., 38, 1068, doi:10.1029/2001WR000861, 2002. 